\begin{tabular}{|c|c|}
\hline 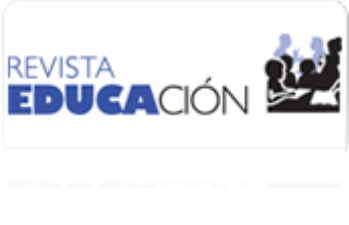 & $\begin{array}{l}\text { Revista Educación } \\
\text { ISSN: 0379-7082 } \\
\text { ISSN: } 2215-2644 \\
\text { revedu@gmail.com } \\
\text { Universidad de Costa Rica } \\
\text { Costa Rica }\end{array}$ \\
\hline
\end{tabular}

\title{
Equilibrios y tensiones en dos décadas de acreditación universitaria en Argentina: Aportes para un modelo conceptual
}

\author{
Marquina, Mónica \\ Equilibrios y tensiones en dos décadas de acreditación universitaria en Argentina: Aportes para un modelo \\ conceptual \\ Revista Educación, vol. 41, núm. 2, 2017 \\ Universidad de Costa Rica, Costa Rica \\ Disponible en: http://www.redalyc.org/articulo.oa?id=44051357003 \\ DOI: http://dx.doi.org/10.15517/revedu.v41i2.21354
}

Esta obra está bajo una Licencia Creative Commons Atribución-NoComercial-SinDerivar 3.0 Internacional. 


\title{
Equilibrios y tensiones en dos décadas de acreditación universitaria en Argentina: Aportes para un modelo conceptual
}

\author{
Balances and Tensions in two Decades of University Accreditation in Argentina: Contributions for a Conceptual \\ Model
}

Mónica Marquina [1]

Universidad Nacional de General Sarmiento, Argentina Redalyc: http://www.redalyc.org/articulo.oa?id=44051357003

mmarqui@ungs.edu.ar

Recepción: 01 Octubre 2015

Aprobación: 23 Marzo 2017

\section{RESUMEN:}

Este artículo se propone realizar un balance de veinte años de experiencia de acreditación de carreras universitarias en Argentina desde la mirada de los actores involucrados: evaluadores, evaluados y responsables políticos y técnicos de los procesos de acreditación. Se parte del supuesto que la implementación de la política de evaluación y acreditación no constituyó un proceso lineal, gradual, ni simple, sino que implicó atender tensiones y contradicciones presentes en el accionar de los distintos actores implicados, y que pueden sintetizarse en tensiones presentes en cada uno de los ámbitos donde operan los actores, a partir de una tensión principal: la de la evaluación como acción fiscalizadora o de construcción de sentidos para el mejoramiento. Se trata, por tanto, de estudiar dichos procesos en toda su complejidad. El artículo enmarca el contexto y las características del sistema de evaluación y acreditación universitaria de Argentina, con foco en el funcionamiento de su agencia de evaluación: La Comisión Nacional de Evaluación y Acreditación Universitaria (CONEAU). Los resultados surgen del análisis de información proveniente de fuentes documentales, entrevistas en profundidad y una encuesta representativa a los sujetos que actuaron como evaluadores. En las conclusiones se propone un modelo conceptual representativo de "la arena evaluativa", en el que se intenta graficar las tensiones y dinámicas de estos procesos complejos. El estudio se realiza desde una perspectiva de la evaluación como procesos políticos, participativos y de construcción de sentidos.

Palabras ClaVE: Acreditación universitaria, aseguramiento de la calidad universitaria, política universitaria.

\section{Abstract:}

This article aims to analyze the twenty years of experience in accreditation of university programs in Argentina from the perspective of the parties involved: evaluators, evaluated, technicians and decision-makers in the accreditation processes. It is assumed that the implementation of policy evaluation and accreditation in Argentina was not a linear, gradual, and simple process. Tensions and contradictions in the actions of the various actors involved are present in each of the areas where parties operate, within a main tension: evaluation for state control or evaluation as construction of meanings for improvement. Therefore, this study aims to study all the processes and their complexity in the context and characteristics of the university system of evaluation in Argentina, focused on the brief history of the estate evaluation agency: CONEAU. The results come from the analysis of information from documentary sources, interviews, and a representative evaluator's survey. The conclusions propose a conceptual model in which attempts to graph "the evaluative arena", with tensions and dynamics of these complex processes. The study is done from a perspective of the evaluation as political, participatory and sense - construction processes.

KEYWORDS: University accreditation, higher education quality assurance, university policy.

\section{NotAS DE AUTOR}

[1] Doctora en Educación Superior por la Universidad de Palermo (Arg.). Master of Arts in Higher Education Administration, Boston College (USA). Licenciada en Ciencias de la Educación de la Universidad de Buenos Aires. Actualmente es profesora regular concursada en el Instituto de Desarrollo Humano (IDH) de la Universidad de General Sarmiento (UNGS). Desde ese cargo dicta las asignaturas "Educación Comparada" y "Política Educativa” y realiza investigación en temas universitarios desde hace más de 15 años. Sus áreas de interés son evaluación universitaria, política y gestión universitaria, y profesión académica. Es directora de la Especialización en Política y Gestión Universitaria en la UNGS, y coordinadora de formación del Instituto del Desarrollo Humano \# UNGS. Es docente de la cátedra de Política Educacional de la Facultad de Filosofía y Letras de la Universidad de Buenos Aires. Dicta cursos de posgrado en temas de política y gestión universitaria. Integra la CD de la Sociedad Argentina de Estudios Comparados en Educación como secretaria general. Ha publicado numerosos artículos en libros y revistas con referato. 


\section{INTRODUCCIÓN}

La evaluación de la educación superior fue un tema privilegiado en las agendas reformistas de la década de los 90. Muchos países de la América Latina, a partir de recomendaciones de organismos multilaterales, instalaron durante esa década sistemas de evaluación universitaria con el fin de establecer mecanismos estatales de aseguramiento de la calidad. En Argentina, la implementación de la evaluación y la acreditación universitaria se materializó con la creación y funcionamiento de una agencia creada para tal fin, la Comisión Nacional de Evaluación y Acreditación Universitaria (CONEAU), la cual lleva adelante una intensa actividad que involucra a numerosos actores individuales e institucionales.

En el presente artículo se intenta dar cuenta de los resultados de la implementación de esta política a partir de las percepciones de los actores involucrados. El supuesto que sustenta el trabajo asume que las políticas públicas, más que acciones estatales generadas de arriba hacia abajo, son resultado de un proceso social construido a partir de la emergencia, desarrollo y resolución de cuestiones que la sociedad -a través del Estado- considera importante para la reproducción del orden social (Oszlak y O'Donnell, 1981). A la vez, las conductas de los actores solo pueden ser comprendidas en tanto forman parte de instituciones, cuyas reglas las moldean y a la vez son moldeadas por ellos (Powell y Dimaggio, 1991). En este sentido, la hipótesis que ha guiado el análisis que aquí se propone sostiene que la implementación de la política de evaluación y acreditación no constituyó un proceso lineal, gradual, ni simple, sino que implicó atender tensiones y contradicciones presentes en el accionar de los distintos actores implicados, y que pueden sintetizarse en una tensión principal: la de la evaluación como acción fiscalizadora o de construcción de sentidos para el mejoramiento (Dias Sobrinho, 2003; 2005; 2006; 2008).

\section{La eVAluación uniVersitaria en Argentina}

En la experiencia argentina, la evaluación universitaria constituyó un instrumento privilegiado de política pública que se instaló en la década de los 90, a la luz de una profunda reforma de la educación superior inscripta en marcos y orientaciones sustentados en la corriente de la Nueva Gestión Pública (López, 2005). Desde el momento de su inclusión en la agenda como cuestión socialmente problematizada, a partir de diagnósticos y datos que reflejaban la existencia de un sistema universitario limitado en su capacidad de atender con propuestas de calidad a la creciente demanda de educación superior, la evaluación universitaria se constituyó en una cuestión controvertida entre el gobierno y la comunidad universitaria. Los procesos de interacción, negociación y disputa formales y no formales de los sujetos involucrados han dado por resultado una configuración específica, y no concluida, de la evaluación en Argentina, producto del "ajuste mutuo" entre el Estado y dichos actores (Camou, 2007). Por tanto, la particular experiencia argentina de la evaluación universitaria está marcada por el modo en que los actores, en el marco de sus instituciones, resistieron, adaptaron, procesaron y recibieron las nuevas regulaciones de la evaluación. Los resultados de esos interjuegos son producto de la combinación de las diferentes lógicas que guiaron su accionar, de sus intereses, de su poder, y de estos en combinación con los de los demás.

Concretamente, el sistema de evaluación y acreditación universitaria se consagra en Argentina con la sanción de la Ley de Educación Superior (Presidencia de la Nación, 1995), en la que se crea la Comisión Nacional de Evaluación y Acreditación Universitaria (CONEAU). La peculiaridad de la agencia de evaluación argentina está dada por la multiplicidad de funciones que le son asignadas por dicha norma, tales como la realización de evaluaciones externas de instituciones cada seis años; la acreditación de programas de grado denominados "de riesgo" ${ }^{22]}$ por comprometer el interés público; y de todos los programas de posgrado. También es la responsable de dictaminar sobre la consistencia y viabilidad de proyectos institucionales, requeridos para la autorización de nuevas instituciones por parte del Ministerio de Educación. También 
elabora los informes previos para el otorgamiento de autorización provisoria o reconocimiento definitivo a instituciones privadas; y se encarga del reconocimiento de entidades privadas de acreditación. Por otra parte, la CONEAU no es un organismo que elabora criterios o estándares de evaluación del sistema, sino que aplica regulaciones definidas por el Ministerio de Educación, que a la vez son consultadas al Consejo de Universidades, que es el ámbito en el que se encuentran representadas el conjunto de las instituciones universitarias, públicas y privadas. No obstante, la agencia sí se encarga de la elaboración de instrumentos de apoyo a los procesos, tales como manuales de pares, guías, y otros documentos.

En este organismo intervienen actores diferenciados. La función política del cuerpo es llevada adelante por doce miembros, personalidades designadas por el Poder Ejecutivo Nacional, los cuales deben ser personalidades de reconocida jerarquía académica y científica, con actuación en gestión educativa, instituciones de la educación superior, públicas o privadas y de investigación científica. Duran en sus funciones cuatro años, con sistema de renovación parcial. Este cuerpo tiene la última palabra sobre los resultados de los procesos de evaluación y acreditación llevados adelante por la agencia.

Todas las funciones de este organismo también prevén la participación de pares académicos evaluadores, personas encargadas de llevar adelante la instancia de evaluación externa de los procesos (tanto de evaluación institucional como de acreditación de carreras), tarea que implica analizar los informes de autoevaluación, realizar visitas a las instituciones y elaborar informes de evaluación externa, con la elaboración de requerimientos y recomendaciones, para su consideración por el plenario de miembros de la CONEAU. Para ello, el organismo ha constituido un registro de pares evaluadores según especialidad, el cual se renueva periódicamente y es utilizado a la hora de la constitución de los equipos.

La organización de las acciones es responsabilidad de un tercer actor en este organismo: los técnicos. Caracterizados como personas con alto nivel de formación provenientes de diferentes disciplinas y que han adquirido en el cargo un conocimiento muy específico relativo a los procesos de evaluación y acreditación universitaria, son los responsables operativos de llevar adelante los procesos evaluativos, haciendo cumplir los estándares y procedimientos generales definidos externamente.

Finalmente, en esta "arena evaluativa" aparece un cuarto actor que es el evaluado, es decir, las personas responsables de carreras e instituciones evaluadas, y sus cuerpos académicos y de gestión, que deben dar respuestas desde las instituciones a los requerimientos de evaluadores, técnicos y miembros en el marco de los procesos de evaluación y acreditación.

Los informes oficiales que dan cuenta de la historia de esta entidad asumen una suerte de línea evolutiva de la experiencia de evaluación argentina, que va de una situación inicial de resistencia y temor por parte de la comunidad universitaria, pasando por una adopción de los procesos y reconocimiento de su utilidad, y llegando a una aceptación creciente. En muchos de los pasajes de esos documentos (Comisión Nacional de Evaluación y Acreditación Universitaria (CONEAU), 2002; CONEAU, 2011; Instituto Internacional para la Educación Superior en América Latina y el Caribe (IESALC), 2007; Isuani, 2003), es posible identificar una idea de la acción de la CONEAU como proceso en evolución. Términos como "aún no se ha logrado", falta llegar a... "si bien al comienzo...en la actualidad..." dan cuenta de una visión de la política de la evaluación como un proceso que comenzó con un diseño e implementación controvertidos, que evolutivamente van hacia el logro de la "cultura de la evaluación", connotando con este término una situación en donde todos los actores involucrados están compenetrados con valores, creencias y acciones en línea con los deseados objetivos del mejoramiento y del cambio. Se intentará a continuación sostener otro punto de vista respecto de la linealidad de este proceso.

\section{FUNDAMENTOS TEÓRICOS}

Analizando la evolución reciente de los sistemas de evaluación universitaria de América Latina, Díaz Sobrinho $(2003,2005,2006,2008)$ brinda aportes teóricos que son de utilidad para este trabajo. El autor 
realiza una distinción entre una mirada neutral y la perspectiva netamente política de la evaluación, es decir, como un espacio social de disputa de valores y de poder. Para el autor, todos los modelos de evaluación se basan en diferentes epistemologías y referencias éticas, que se corresponden con concepciones básicas de sociedad, diferentes intereses y visiones de futuro. "Por eso se debe reconocer que la evaluación de la educación superior es un campo de conflictos, tensiones y disputas, de espacios de poder” (Díaz Sobrinho, 2003, p. 71). Ninguna evaluación está exenta de valores y subjetividad. Su operacionalización está cargada de actitudes valorativas, interpretaciones, intereses e ideologías, y no puede ser vista por fuera de las realidades históricas y sociales.

Pensar en la evaluación como ámbito político implica reconocer la existencia de contradicciones, dadas por la presencia de variados sectores y grupos.

Como no hay homogeneidad en esos grupos ni ellos producen consensos perfectos y duraderos respecto de las políticas de educación superior, hay que pensar en contradicciones internas y externas: contradicciones entre los distintos grupos de la comunidad educativa superior; entre partes de esa comunidad y sectores del gobierno, entre segmentos de la administración central, etc. ... Las tensiones y los problemas más complicados no son los técnicos, y sí, todo aquello que envuelve a actores e intereses. (Dias Sobrinho, 2006, p. 172).

Por ello, la evaluación no debe ser determinante, como una demostración definitiva de la verdad. Más bien su función es la de generar procesos reflexivos que produzcan sentidos respecto de las acciones.

También por esta razón es que hay que considerar que los evaluadores (los mediadores de la evaluación) y los evaluados (que en muchos sentidos también son evaluadores) son co-actores esenciales ... Uno no podría existir sin el otro. La evaluación ... debe ser esencialmente una cuestión de cada cual sobre sí mismo enfrente del otro, en una situación concreta de interrogación sobre los significados de las prácticas sociales. En este sentido, la evaluación es también un proceso de formación de la apropiación de los significados de las experiencias, situaciones y proyectos de vida. (Dias Sobrinho, 2008, p. 205).

Para el autor, en esta arena de disputa y contradicciones ha prevalecido, con fuerza en las últimas décadas, una "ideología de la competitividad", incorporada por los gobiernos, cuyas palabras clave son productividad, eficiencia, efectividad, flexibilidad, confiabilidad, previsibilidad, comando, control, gestión; todas palabras provenientes de la lógica de la economía. Más que responder a un imperativo educativo, desde este marco la evaluación se ha visto restringida a responder a una presión externa caracterizada por la maximización del individualismo y la competencia por parte de sujetos e instituciones que deben probar su accionar en base a estos principios.

La prevalencia de una mirada de la evaluación como control y medición es un tema recurrente de varios estudios. La principal consecuencia del predominio de esta perspectiva instrumentalista es el crecimiento de la burocratización y en el fortalecimiento de las administraciones centrales de cada institución para afrontar los procesos de evaluación externa. Al respecto, Neave (2001), menciona la "instrumentalidad abrumadora" que emerge de estos procesos, tendiente a inducir a los académicos a cumplir con los objetivos, las metas y los fines de los dirigentes. Para Díaz Barriga (2005, p. 6), estos cambios implicaron "la capacidad institucional de mostrar el incremento de una serie de indicadores" quitándole tiempo a otras actividades sustantivas de la universidad. Para Porter (2003), estos cambios han dado lugar al concepto de universidad de papel. Paradójicamente, la información generada raramente es objeto de retroalimentación institucional para la reflexión acerca de lo que la institución hace, aunque sí puede constituir un factor de legitimación y diferenciación en el mercado (Buendía, 2011a y 2011b). Finalmente cabe mencionar a Corengia (2015), quien sostiene que aun cuando puedan observarse cambios, estos principalmente obedecen a "estrategias adaptativas de las instituciones ante regulaciones del Estado" (p. 467).

La evaluación como control se diferencia de una mirada más completa de la evaluación, "distinta de un retrato momentáneo de una realidad fija" (Dias Sobrinho, 2003, p. 37), que implica una construcción colectiva de sentidos éticos, políticos y filosóficos que se da una comunidad académica con el propósito de un mejoramiento permanente. Para el autor, evaluación y control no deberían ser vistos como conceptos antagónicos, aunque tampoco subsumir al primero en el segundo. El control sin cuestionamiento y reflexión 
es simplemente medida, verificación, actitud burocrática y conservadora. Por su parte, evaluación sin procedimientos, mediciones y otros aspectos objetivos carecería de los trazos básicos para la reflexión, la producción de sentidos. El autor propone una reinstitucionalización de la educación superior, es decir, una recuperación de su sentido de institución social que contribuye a la formación intelectual autónoma para la lectura crítica de la historia y la formación de la conciencia del papel de las ciencias. En este marco de reinstitucionalización, la evaluación forma parte de un proceso de autonomía y de emancipación, al colaborar en la construcción de sentidos de la institución universidad y, por ende, colaborar con la cultura y con todo proceso civilizatorio y educacional.

\section{Metodología}

Este trabajo presenta resultados de una investigación de tipo explicativa desarrollada entre 2008 y 2013 , que se propuso estudiar la experiencia argentina de acreditación universitaria de carreras de grado y posgrado en su complejidad. En función del marco teórico establecido, se analizó la implementación de la política de acreditación privilegiando tres miradas: 1) La de la agencia, a través de los miembros y técnicos de la CONEAU; 2) la de los pares evaluadores, académicos reconocidos provenientes de los diferentes campos disciplinares de las carreras evaluadas, y c) la de los "evaluados", es decir, autoridades de carreras que fueron objeto de acreditación, en general profesores reconocidos en su disciplina en el nivel de la conducción de las instituciones. Se han seleccionado estos actores porque ellos despliegan sus acciones vinculadas con la evaluación en ámbitos diferenciados de la coordinación universitaria (Clark, 1991). Los pares evaluadores lo hacen en el ámbito de la oligarquía académica; los miembros y técnicos en el ámbito del Estado; y los evaluados en un mercado de carreras en el que compiten por prestigio y supervivencia (ver Figura 1).

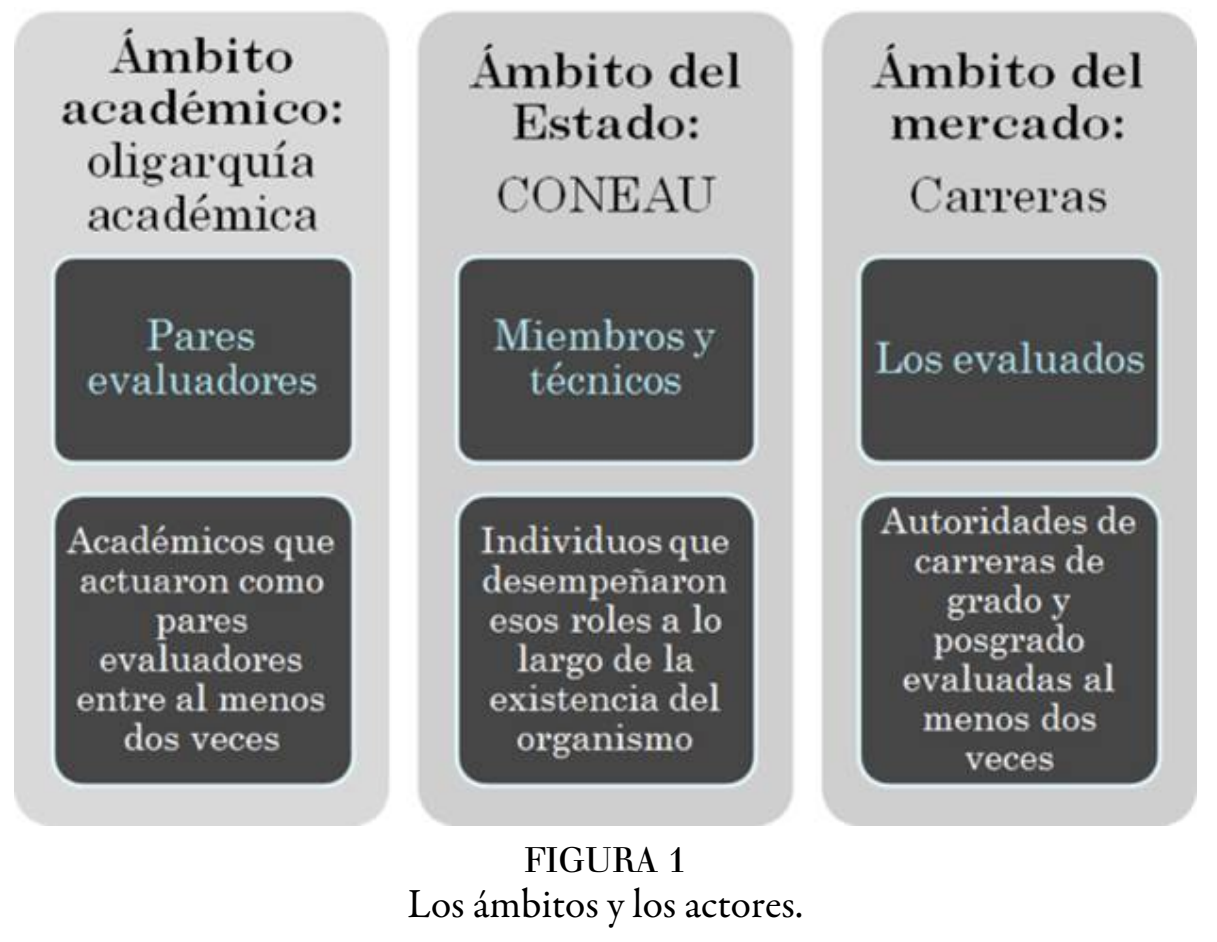

La investigación ha utilizado la estrategia de "métodos múltiples" o "investigación multimétodo" (Bryman, 2004, citado por Archenti y Piovani, 2007), para hacer referencia a la "triangulación” de metodologías de abordaje cuanti y cualitativas. En este sentido, recoge información de fuentes documentales y de dos trabajos de campo, uno a partir de una muestra aleatoria incidental a la que se administró un cuestionario estructurado $(\mathrm{N}=184)$ que tuvo por objeto recuperar la experiencia de evaluación de los pares evaluadores ${ }^{[3]}$; el otro, a 
partir de la realización de sesenta y cuatro entrevistas a diferentes actores, con base en un diseño metodológico específico según cada actor, construyendo muestras intencionales de grupos de actores a los que se entrevistó a partir de guiones diferenciados y no estructurados. Para el caso de las entrevistas a miembro de la agencia y técnico, se trató de un guión abierto y flexible, que tuvo como objeto recolectar sus percepciones sobre los procesos de evaluación así como la actuación de los otros actores, e intentó reflejar tanto el consenso de las respuestas entre cada grupo de actor, como el conflicto o diferencias. Para el caso de las entrevistas a evaluadores y evaluados (ver Tabla 1), se trabajó con guiones semiestructurados que intentaron captar el consenso en las respuestas relacionadas con sus percepciones sobre el proceso de acreditación experimentado, opiniones sobre los evaluadores y sobre el dictamen final, y la influencia de dichas recomendaciones en el desarrollo posterior de la carrera, focalizando algunas diferencias según el tipo de carrera (grado - posgrado) y el tipo de institución (pública - privada) ${ }^{[4]}$.

TABLA 1

Muestra intencional de personas entrevistadas

\begin{tabular}{lllll}
\hline & Actor & Cantidad & $\begin{array}{l}\text { Características } \\
\text { guión }\end{array}$ & $\begin{array}{l}\text { Criterio selección } \\
\text { de testimonios }\end{array}$ \\
\hline CONEAU & Miembros & 6 & Abierto / flexible & $\begin{array}{l}\text { Reflejo del conflicto y } \\
\text { del consenso }\end{array}$ \\
\cline { 2 - 3 } & Técnicos & 10 & & \\
\hline Pares & Grado & 10 & Semi estructurado & Reflejo del consenso \\
\cline { 2 - 3 } & Posgrado & 10 & Semi estructurado & Reflejo del consenso \\
\hline Evaluados & $\begin{array}{l}\text { Grado } \\
\text { públicas }\end{array}$ & 10 & & \\
\cline { 2 - 3 } & $\begin{array}{l}\text { Grado } \\
\text { privadas }\end{array}$ & 5 & & \\
\cline { 2 - 3 } & $\begin{array}{l}\text { Posgrado } \\
\text { públicas }\end{array}$ & 8 & & \\
\cline { 2 - 3 } & $\begin{array}{l}\text { Posgrado } \\
\text { privadas }\end{array}$ & 5 & & \\
\hline & & 64 & & \\
\hline Total & & & & \\
\hline
\end{tabular}

En este artículo se muestran resultados de la investigación que surgen en parte del trabajo de campo realizado con la encuesta a pares evaluadores (Marquina, Ramírez y Rebello, 2009) y fundamentalmente de las entrevistas. Por cuestiones de espacio, se citarán los testimonios más representativos de cada conjunto de respuestas por actor obtenido.

\section{ANÁLISIS DE RESULTADOS}

\section{El entramado de tensiones entre agencia, evaluadores y evaluados}

Los testimonios recogidos permitieron, en principio, comprobar que la evaluación, en el marco de la política pública, constituye un espacio en el que los actores involucrados se apropian de las nuevas reglas de juego y las incorporan a su accionar cotidiano articulándolas de diferentes formas con sus prácticas. Esta nueva situación ha generado, a la vez, nuevos vínculos entre esos actores, constituyendo un entramado de tensiones que nos aleja de la visión lineal y gradual de política pública que comienza en su diseño, pasa por su implementación y concluye en su consolidación y éxito. 
En lo que sigue, se intentará interpretar el accionar de cada uno de los actores en sus ámbitos y de ellos con el resto; cómo se ha configurado esa apropiación de la evaluación como instrumento de política pública en sus años de existencia y qué lugar hoy ocupan estos actores en la arena evaluativa. Por cuestiones de espacio, a pie de página solo se citan algunos testimonios de las entrevistas que mejor representan los hallazgos analizados.

\section{El ámbito del Estado: La CONEAU. Miembros y técnicos entre la lógica burocrática y la lógica politica}

La CONEAU es la agencia gubernamental encargada de llevar adelante la política de evaluación y acreditación en Argentina y ha asumido la función de regulación del funcionamiento de carreras de grado y posgrado. Allí son dos los principales actores que dan vida a su funcionamiento: los técnicos y los miembros. A lo largo de la experiencia de veinte años, se observa en los técnicos el desempeño de un rol cambiante. Desde la norma, inicialmente sus actividades quedaron pautadas de manera clara y precisa, en la figura de "asistencia" a los procesos evaluativos, plasmados en la responsabilidad de elaborar un informe técnico que llegaría a la instancia de decisión al mismo nivel que el informe valorativo de los pares evaluadores. A lo largo del tiempo, ese lugar de importancia varió, ya que se redujo el valor del informe del comité de pares, al poder decidir una ampliación por parte de los miembros o constituir otro comité y obligar a tomar al informe técnico como un instrumento de similar valor a la presentación de la institución y su informe de autoevaluación ${ }^{[5]}$. El rol crecientemente relevante del técnico a lo largo del tiempo también se ha advertido en la propia práctica. Los testimonios de los miembros y los propios técnicos evidencian la responsabilidad de este actor en garantizar informes de evaluación de calidad atentos a las normas vigentes, para lo cual acompañan de manera muy firme el trabajo realizado por los pares, e incluso incidiendo en esa tarea.

El rol del técnico como intermediario, como catalizador del proceso, es fundamental. Lo pienso desde un punto de vista inmediato, procedimental, porque mi responsabilidad era producir resoluciones. Buscar la mejora es fantástico, pero yo tenía que producir la mayor cantidad en el menor tiempo posible. ... El técnico es la guía, el que le da continuidad al proceso de producción de elementos que luego sirven como insumos para la mejora. (Testimonio de un técnico)

El equipo técnico cumple la función de asesoramiento a los pares. Hay fuerte influencia del equipo si tiene buena experiencia. Tienen la responsabilidad de garantizar que esté el trabajo en tiempo y forma. El técnico ayuda a poner algunos límites en la tarea del par, lo que se puede y no ...También asesora en la manera de redactar, sobre cómo armar un dictamen. Se armaron instrumentos para garantizar un discurso argumentativo, cómo se estructura, cómo utilizar la información para fundamentar la evaluación. El técnico se asegura que el informe del equipo de pares reproduzca ese proceso para convencer al lector del juicio. (Testimonio de un miembro)

...hay una "inducción" por parte del técnico. No sé si es una política o el modo en que ellos interpretan su rol. A mi concretamente me discutieron amablemente (el técnico era un pibe) y me transmitió su idea sobre la carrera, de "bocharla" ...Yo parto de la base, y en eso sí que no tengo duda, de que los técnicos ya tienen una opinión formada. Ellos asumen un rol de manejo: te llevan de la mano. Cuando se asumen esos roles se establece una relación desigual. El técnico es el que sabe y vos el que no, hay una relación de poder que se plantea naturalmente. (Testimonio de un par evaluador)

Por su parte, los miembros como cuerpo tienen la última palabra sobre los resultados de los procesos de evaluación y acreditación llevados adelante por la agencia. El modelo inicial de organización de la agencia, encuadrado en el sistema de gerenciamiento, fue modificado posteriormente para ir hacia un modelo que da espacio al reconocimiento del conflicto y la negociación ${ }^{[6]}$. El criterio general de regulación fue inicialmente el de convertir a la agencia en una suerte de organismo aplicador de criterios y pautas preestablecidos. Para ello, la figura del entonces director ejecutivo reunía las principales características de la alta gerencia, donde los criterios de racionalidad instrumental se aplicaban en estos casos de manera explícita ${ }^{[7]}$.

La complejidad de los procesos llevados adelante, la conflictividad con los actores universitarios, así como la tensión entre las diferentes concepciones acerca de la evaluación, entre otros aspectos, definieron el devenir de la agencia hacia una opción en donde el componente político, materializado en la tarea de lo miembros, 
fue siendo más fuerte. Este componente político de la agencia, que fue midiendo paso a paso la forma en que se implementaban los procesos, posibilitó una aceptación creciente de su función en las instituciones, con la consecuente reducción de la resistencia inicial.

Aparecieron así, a lo largo de los años, dos modelos de organización en tensión, que impactaron en la tarea de los actores involucrados, uno de naturaleza típicamente gerencial, detrás del cual predominó una concepción de la evaluación como control, y otro que reconoce el espacio de la discrecionalidad a fin de no transformar la tarea evaluativa en una maquinaria impersonal, modelo que podría vinculárselo más cercano a la concepción de evaluación como mejora. Esta opción, según algunos sujetos entrevistados de la agencia, hubiera provocado la muerte del sistema que se estaba gestando e implementando.

Si la CONEAU no hubiera tenido a los doce miembros con un perfil más político que académico nunca hubiera podido instaurarse la evaluación en el sistema universitario. ... si la CONEAU hubiese estado integrada por investigadores principales del CONICET hubiese estallado en mil pedazos a las pocas semanas de crearse, porque hubiesen aplicado los estándares desde la visión más extrema y ultramontana, y eso no era lo que el país necesitaba ni probablemente lo necesite en este momento de desarrollo del sistema universitario. Por eso cuando se dice que la CONEAU está politizada, si es que con ello se hace referencia a que las decisiones que se toman son diferentes del juicio de los pares, yo te digo bienvenido sea, porque de lo contrario hoy la CONEAU no existiría, no le hubiera servido al sistema universitario, porque no se hubiese desplegado este sistema virtuoso de incremento de la calidad que estoy convencido que se desató. (Testimonio de un coordinador técnico)

El cambio de modelo fue una condición para el logro de cierta legitimidad al asumir este carácter ambivalente, de una racionalidad técnica dada por la aplicación de instrumentos, balanceada por la racionalidad política provista por los miembros, que en definitiva tienen la última palabra en los resultados. Este equilibrio parece haber sido exitoso en la primera etapa de desarrollo de la agencia, porque estuvo mediado por la reflexión permanente sobre los procesos que se diseñaban e implementaban, con el rol destacado de algunos miembros que motorizaban esos procesos de reflexión interna de la agencia.

Con el paso del tiempo, y la instalación gradual de los procesos diseñados, la agencia fue experimentando la dificultad de poder responder a una demanda creciente de actividad, que redefinió los espacios para la reflexión sobre los procesos y su perfeccionamiento permanente. En términos de distribución de tareas, la actividad de reflexión se escindió de cada una de las áreas encargadas de las diferentes funciones de la agencia, y se concentró en un ámbito que es visto como ajeno y funcionando en otros tiempos diferentes de la urgencia permanente de las áreas más comprometidas con el trabajo cotidiano ${ }^{[8]}$. Este cambio estructural se sumó a una progresiva transformación del perfil de los técnicos. El alto nivel de rotación y recambio producto de un perfil muy particular del técnico con intereses en la academia, se va transformando por las precarias condiciones de contratación, sumado a la creciente actividad de la agencia generadora de presión en su trabajo; lo que provocó la constitución de un cuerpo técnico menos formado y más orientado a la aplicación de las normas e instrumentos.

Sí, hay recambio. Se debe al sueldo, pero también a falta de perspectivas académicas, de crecimiento, de formación. Vos estás tomando a un graduado, joven, generalmente con un posgrado, que luego se va, que no necesariamente tiene formación en educación y menos en evaluación. Van por trabajo, por experiencia. Pero se van porque hay un techo. Si no te gusta, esto es muy rutinario: 8 hs. a full y cuando viajás, 24. (Testimonio de un técnico)

Hoy es un grupo nuevo. Y a la gente nueva le falta mucho. Ahora se van formando en la práctica. Deberían tener conocimientos sobre el sistema universitario que no tienen. Son recién graduados. Se forman en la práctica, van con los técnicos viejos. Y aprenden, no tienen otra. (Testimonio de un técnico)

Por su parte, el perfil de esos miembros con liderazgo y capacidad de revisión permanente que predominó en los comienzos también parece haber ido cambiando. La burocratización, en este sentido, pareciera estar ganando espacios a la autorreflexión sobre los procesos, característica del momento inicial de funcionamiento de la agencia. Este escenario estaría dando mayor espacio a la faceta de la evaluación como instancia de 
cálculo, medición y neutralidad, vinculada al control, frente a una mirada de la evaluación como expresión de tensiones y construcción de sentidos entre los actores participantes de los procesos (Días Sobrinho, 2008).

\begin{abstract}
Estoy casi seguro que hoy los miembros no entienden lo que hace la CONEAU. Ya no son personas reconocidas en el campo de la educación superior. Ahora sí es la "governance” de los técnicos, como había sido la idea originaria. Si, había una tensión al principio de una comisión de notables y un secretario ejecutivo y eso no funcionó. Hoy en los hechos hay una suerte de centro gravitacional que vuelve torciéndolo en ese sentido hacia el cuerpo técnico, al que el presidente se aferra. Hoy no sabes quién va a ser miembro, alguien que está haciendo banco para ser diputado, un especialista en un campo específico que no tiene la foto del conjunto del sistema, o alguien que se lo premia. (Testimonio de un coordinador técnico)
\end{abstract}

Este desequilibrio se profundizó con la ambigüedad normativa existente respecto de la función consultiva o resolutiva de la CONEAU. Con el paso del tiempo, la agencia ha pasado a ocupar un lugar determinante en el proceso de reconocimiento oficial de los títulos. La propia agencia, a través de sus actores, reconoce que esta función colabora aún más en reforzar el aspecto burocrático asociado a una función de control y fiscalización gubernamental.

Y la CONEAU tendría que pensar en modificar su praxis, para salir de la burocratización, porque la masividad del laburo, que no es saturación, hace que se convierta sin quererlo, porque hay esfuerzos tremendos, en una factoría de producir actos resolutivos, que además están subsidiando procesos que está dejando de hacer el Ministerio...Esto es preocupante porque todo se va acomodando en ese lugar, y en veinte años vamos a tener personas que reciben papeles, ponen sellos, y esa imagen a mí me aterroriza. Pero la inercia lo lleva a eso. Y además hay otra amenaza, y es que la CONEAU crezca en términos exponenciales como el sistema. Y la CONEAU está haciendo de reguladora del crecimiento a través de sus evaluaciones. Si querés evaluación de calidad no podes tener como ahora 200 proyectos de posgrado en abril y otros tantos en noviembre... Se deberían imaginar alternativas en el ámbito del Consejo de Universidades para imaginar cómo salir de este atolladero. (Testimonio de un miembro)

La percepción de una agencia anclada en la puesta en marcha de procesos burocráticos y de control también es una percepción de los evaluados. A las críticas vinculadas con la saturación de las tareas y problemas en los instrumentos diseñados para el llenado de información, se suman otras referidas a su limitada capacidad para preparar adecuadamente el trabajo de los evaluadores, proveyéndoles información y capacitándolos.

[Las recomendaciones] fueron totalmente inútiles. Lo peor es que la gente que evaluó era buena, eh. Pero yo digo, no le informaron bien... Es que hicieron observaciones ridículas, observaciones que ninguna nos servían... Yo creo que pasó esto por la falta de información de los pares; y yo creo que la CONEAU no tenía gente para evaluar .... Pero me llama la atención porque los nombres son gente "buena"; me parece que hubo quizás falta de información. (Testimonio de un evaluado de posgrado) (Marquina, Ramírez y Rebello, 2009, p. 71)

Pese a que la agencia ha ido incorporando en el diseño de los instrumentos de acreditación un componente orientado a la mejora de las carreras, en el marco de sus contextos institucionales, los evaluados, lejos de percibir al trabajo de la CONEAU como un aporte al mejoramiento de sus propios procesos, conciben a la agencia como un organismo de control y también como de regulación de un mercado en crecimiento.

Estas tendencias son motivo de preocupación de algunos directores y miembros comprometidos en el proceso de pensar cómo debería continuar una política pública de acreditación luego de esta experiencia de veinte años. Pese a no haber respuestas acabadas para este interrogante, hay evidencia de que el tenso equilibrio que ha sostenido a la agencia se ha desbalanceado y que es necesario que la propia organización haga consciente esta circunstancia en un proceso autorreflexivo que debe recuperar.

\title{
El ámbito de la oligarquia académica: Los pares evaluadores. Saber experto vs. podery autoridad en el campo
}

Uno de los campos que atraviesa la acreditación de carreras es el académico (Bourdieu, 1983, 1988). Los evaluadores, en tanto miembros de ese campo, pertenecen a comunidades disciplinares en donde ponen en 
juego su prestigio y autoridad para decir la verdad acerca de la calidad de una carrera. La evaluación por pares es el mecanismo legítimo dentro del campo científico y académico para la reproducción del conocimiento (Roy, 1984). Ellos poseen un saber específico que los coloca en un lugar incuestionable a la hora de necesitar una opinión autorizada sobre la calidad del trabajo de sus colegas.

En este marco, el sistema de evaluación universitario argentino, en función de sus propósitos, ha dado un lugar clave a la participación de los pares académicos. "Esto se observa en la normativa que regula la tarea de los pares evaluadores y en los instrumentos que progresivamente la agencia fue elaborando y ajustando para guiar su trabajo. Podría decirse que estas previsiones han sido fructíferas para el logro de los objetivos de la evaluación ya que, pese a las variadas críticas a la tarea del par evaluador, hoy nadie cuestiona la existencia de ese rol" (Marquina, Ramírez y Rebello, 2009, p. 74). No obstante, entre las mismas características que hacen a este reconocimiento se encuentran otras que colocan en tensión su trabajo, y que provienen de su pertenencia a campos disciplinares o bien a ámbitos institucionales específicos que pueden provocar miradas sesgadas en los juicios que realizan. Con el concepto de "particularismo cognitivo" (Travis y Collins, 1991) se describen aquellos casos en los que los evaluadores emiten juicios sesgados a fin de preservar ciertas visiones, escuelas o corrientes de pensamiento al evaluar una investigación para su financiamiento o un artículo para su publicación. El rol del evaluador en estos casos opera como "guardián" del conocimiento consolidado o hegemónico en determinado campo del saber, aunque también respecto de la preeminencia de determinados grupos, o colegas provenientes de ámbitos geográficos, institucionales, género, etc.

En el caso de la acreditación de carreras, el posgrado es el área en donde se presentan de manera más clara los sesgos disciplinares o de poder de los grupos académicos, por ser ese ámbito el más cercano al campo científico, mientras que en la acreditación de carreras de grado abundan sesgos asociados más a la pertenencia institucional del evaluador, o bien respecto de una idea previa del "deber ser" proveniente de la proyección de su propia experiencia.

De los testimonios analizados se ha visto que son los evaluados quienes más se quejan de estos sesgos, especialmente por el efecto que pueden generar respecto de la imposición de modelos homogéneos institucionales o de carreras, así como de pensamientos únicos. Se ha advertido la existencia de sesgos por la preponderancia de una visión proveniente de la universidad pública sobre juicios vinculados a la organización institucional, o existencia de prejuicios respecto de la calidad del funcionamiento del ámbito privado que determinan a priori un juicio negativo. También se ha reconocido la existencia de sesgos sobre concepciones específicas y predominantes acerca de lo que significa la atención primaria en el campo de la medicina, así como se han observado sesgos en las concepciones respecto del lugar y características que debe tener la investigación en el desarrollo de una carrera, por ejemplo, en las carreras de grado de ingeniería, que estaría mostrando el predominio de miradas academicistas en las evaluaciones de carreras más profesionales.

Sesgos hay. Por ejemplo, la mayoría de los pares son de universidades públicas. Hay una comprensión hacia las públicas mayor que hacia las privadas, sobre la base de que son mejores. Hay una mejor disposición (quizá sabiendo del esfuerzo, falta de recursos). Cuando hay una irresponsabilidad en el manejo de recursos, se ponen duros. Se indignan por el mal uso: 'no pueden tener todo esto y no hacer algo medianamente bueno'. (Testimonio de un miembro)

Con respecto a la atención primaria, los estándares dicen que son atenciones de cuidado a la población, atenciones de promoción de la salud, y los pares -y eso no está escrito en ningún lado- nos exigieron que tuviéramos actividades en áreas rurales. Y eso forma parte de una visión sesgada de la atención primaria. No lo dice en ningún lado, pero esos pares querían ver eso.

Y más adelante continuó diciendo:

...hubo que fundamentar mucho en el informe de respuesta ... y generó -al menos entre nosotros- incomodidades. (Testimonio de un evaluado, autoridad responsable de la acreditación de medicina de una universidad privada)

Este punto no solo se ha reconocido en los testimonios obtenidos, sino que se hizo presente en las evaluaciones a la CONEAU, así como también en los resultados de la encuesta realizada a pares evaluadores, 
que muestra un perfil predominante de dedicaciones exclusivas y preferencia por la investigación más que por la docencia que no es representativo del conjunto de los académicos en el país.

Dado que la evaluación por pares es el mecanismo legítimo para la evaluación de carreras, y no está en discusión, el principal interrogante es cómo evitar estos efectos no deseados. En sintonía con la bibliografía vinculada (Díaz-Barriga, 2000; Fortes y Malo, 2002; Harvey, 1999; Pilot, 2001) los sesgos inevitables de los evaluadores se neutralizan principalmente con ajustes en los instrumentos provistos por la agencia para guiar el trabajo del evaluador, así como con capacitación. Los miembros y técnicos de la agencia son los actores que principalmente distinguen estos problemas y trabajan para neutralizarlos. A lo largo de los años de existencia de la agencia se han ido perfeccionando estos instrumentos, aunque de la información relevada y analizada no se advierte un trabajo efectivo en la capacitación del par evaluador. Persisten, al interior de la agencia, diferencias producto de la tensión entre capacitar a un equipo estable de evaluadores, lo que generaría precisión en la aplicación de la metodología pero reforzaría la consolidación de visiones particulares, o la rotación de evaluadores, que aseguraría la pluralidad de visiones; pero acarrearía una dificultad en la capacidad de evaluar a partir de la adquisición de un conocimiento específico. Un miembro que privilegia la calidad por sobre la rotación manifestó:

Cuando funciona bien el par se trata de llamarlo de nuevo. Siempre se trata de que haya en los equipos algunos con experiencia. Además, en grado se los formó con otros pares con más experiencia, sobre la base de reuniones de consistencia, qué mirar y cómo, por eso se justifica cierta estabilidad del elenco de pares.

Desde su propio origen, cómo mejorar el trabajo de los pares es un asunto pendiente en la agencia, que se constata en testimonios y también en documentos de evaluación interna y externa de la CONEAU.

Para los responsables de carreras evaluadas, los sesgos de sus colegas se vinculan con el poder dentro de un campo específico, es decir, con el excesivo uso de la autoridad que le confiere el rol de evaluador o evaluadora para delimitar las características de la enseñanza de grado y posgrado en un área disciplinar determinada. Algunos evaluados han dejado traslucir en sus testimonios el desconocimiento la autoridad de los pares para evaluar.

A mí me pasó algo sorprendente en la última evaluación. Yo creo conocer a casi todo el mundo en mi campo ... pero una de las cosas que yo noté es que de esos 20 o 30 (pares) el $70 \%$ yo no los conocía. (Testimonio de un evaluado)

Hay mucho lobbie en el proceso de selección de pares, sobre todo en posgrado. Por cuestiones de pertenencia, ideológicas, vinculación institucional, que operan sobre los miembros de la comisión. Para comités más benévolos o más drásticos. (Testimonio de un miembro)

En la percepción de los problemas reconocidos respecto del rol del par evaluador, dentro del campo académico pareciera advertirse un conflicto entre evaluadores y evaluado, lo cual se vincula a tensiones provenientes de la procedencia de un mismo campo disciplinar.

Fuera de esta tensión proveniente del campo académico, los evaluados esperan obtener de los juicios evaluativos de sus pares el aporte autorizado y reconocido de una persona experta, con el fin de colaborar con la mejora de sus procesos. Sin embargo, encuentran problemas diversos en la actuación de sus colegas, la mayoría ya reconocidos en la bibliografía existente sobre el tema: desconocimiento de la tarea que se espera realicen, poca preparación, sesgos por procedencia institucional, sesgos disciplinares, sesgos por la propia experiencia personal.

Por su parte, los evaluadores se sienten con autoridad legítima para desarrollar la tarea, y en general, en la opinión de la agencia, se comprometen con esta misma. Mayoritariamente aceptan participar como evaluadores y, aunque explícitamente manifiestan desconocer los motivos de su selección, se puede presumir que la notoria aceptación en la repetición de las invitaciones por parte de la CONEAU se debe a que este rol constituye un mecanismo de distribución de prestigio (Becher y Trowler, 2001) y constituye un capital valorado dentro de su actividad académica. Sin embargo, es importante considerar en este punto 
la preocupación de técnicos y miembros en la dificultad de asegurar las cantidades necesarias de pares evaluadores, en virtud del crecimiento de la actividad de acreditación.

\section{El ámbito del mercado: Los evaluados. entre la simulación y el cambio}

En materia de acreditación, los evaluados actúan en una suerte de mercado de carreras de grado y posgrado. Los bienes que se distribuyen a partir de los resultados de las acreditaciones son materiales y simbólicos. Las carreras de posgrado son las que más compiten por bienes materiales, dado que su existencia depende de la cantidad de alumnado interesado en cursar la carrera y, por tanto, pagar por ella. El sello CONEAU es valorado y difundido a la hora de promocionar las carreras para captar inscripciones, a la vez que es un bien necesario para recibir estudiantado becario financiado por organismos públicos.

Sin embargo, el valor material de la acreditación también está presente en las carreras de grado, a partir de la instauración de programas de financiamiento por parte del Ministerio de Educación para la puesta en marcha de los planes de mejora surgidos como consecuencia de la acreditación. El bien simbólico por el que compiten las carreras es el prestigio y la exclusividad en el ejercicio de ciertas actividades dadas por el artículo 43 de la LES y los estándares. La acreditación funciona como un sello de calidad necesario para las carreras e instituciones en desarrollo, pero también como elemento necesario para mantener el prestigio en las ya consolidadas, frente a su obtención por parte de las anteriores.

En este marco, la política de acreditación fue adoptada y procesada por los evaluados de diferentes modos, de acuerdo con la situación previa en la que se encontraban. Algunas carreras aprovecharon el nuevo marco legal para incorporar a su interior procesos que colaboraron en su organización.

[El proceso de acreditación] sí, sirvió. Mira, agregó, en el sentido que nosotros no hubiéramos hecho jamás esta autoevaluación. Hoy los nuevos estatutos tienen previsto la evaluación de los Departamentos, lo que la gente publicó, no publicó, ese tipo de cuestiones... pero nunca hubiésemos tenido esto de que toda la universidad o que una carrera completa sea evaluada ... Creo que fue un nuevo éxito pensar que esto había que tomárselo en serio; en serio quiere decir: "Veamos cuáles son los problemas". Y después muchos de esos coincidían con los de la CONEAU, y en otros salían nuevos temas, algunos -a mí me parece- que no son críticas válidas, y otros que me parecían adecuados, y está bien que lo hagan, que digan todo lo malo. (Testimonio de un evaluado) (Marquina, Ramírez y Rebello, 2009, p. 70).

Otras, con fines más pragmáticos, aceptaron las nuevas reglas de juego respondiendo a estas mismas como requisitos externos, adoptando estrategias adaptativas:

Mirá, no te voy a mentir, la acreditación sirvió para posicionarse en el sistema, ante otras carreras similares. No sé si es una cuestión de mercado, en el sentido que sirve para atraer más estudiantes, pero sí para mostrar a otras unidades que somos buenos, prestigio. (Testimonio de un evaluado)

En carreras ya consolidadas, la visión de la acreditación como control y obligación parece haber permanecido, aunque en otros casos, estos procesos que fueron inicialmente asumidos como obligación hayan ido penetrando e incorporándose como nuevo elemento al funcionamiento histórico de la carrera.

Hay una realidad dada, o sea, hay que hacerla. Nunca se me hubiera ocurrido pasar por ese proceso. No porque no esté de acuerdo con procesos de evaluación, sino porque estos procesos se han dado y se están dando en un marco político institucional que no tiene por finalidad la creación de condiciones que permitan el mejoramiento de las carreras o de las instituciones, sino más una finalidad de ajuste de las instituciones a un modelo previamente definido; no desde las instituciones, sino desde el aparato del Estado. Entonces, si no hubiera sido obligatorio, no nos hubiéramos presentado. Por otro lado, el planteo nuestro en ese momento fue: "Estamos seguros que se va a presentar cualquiera, con cualquier oferta, y van a poder lucir en la chapa 'acreditado por CONEAU', 'categorizado por CONEAU '”. Y nosotros estamos seguros que hemos armado una propuesta digna y no nos podemos quedar afuera. (Testimonio de un evaluado)

...me parece que es importante porque ha ayudado, con sus más y sus menos. Creo que tiene muchas cosas cuestionables, creo que tiene muchas cosas por mejorar... diez mil cosas! Pero en lo referido a -lo que yo conozco más a fondo- Carreras de Medicina, ayudó a levantar el piso de calidad, y ayudó a fijar un piso. No te olvides que nosotros estamos acreditando 
por estándares que son mínimos. Éstos no son estándares de excelencia. Es como para poner a todos a la altura del zócalo, y después de ahí cada cual verá donde quiere llegar. Me parece que fue de utilidad, porque las carreras estaban impartiendo educación médica pésima. (Testimonio de un evaluado)

Interesa analizar el sentido de estas transformaciones al interior de las instituciones. A diferencia de los documentos oficiales de la CONEAU así como las evaluaciones externas realizadas al organismo que destacan la existencia de un proceso gradual de legitimación del trabajo de la agencia (CONEAU, 2002; CONEAU, 2011; IESALC, 2007; Isuani, 2003), los testimonios de los evaluados ponen en cuestión la aparente linealidad de este proceso. A lo largo de los veinte años, diferentes han sido los modos en que se procesaron esas nuevas reglas de juego a nivel de la institución, en una suerte de combinación de esas reglas con las internas.

Hay algunos aspectos comunes en las respuestas de los evaluados que merecen ser reconocidos como patrones que no necesariamente han evolucionado en algún sentido claro. Por ejemplo, como hemos visto, son comunes las quejas de los evaluados al funcionamiento del proceso de la acreditación. No se ha observado una tendencia de reducción de esas críticas, que podría dar cuenta de un proceso de perfeccionamiento por parte de la CONEAU en sus procedimientos. Para los evaluados, los problemas de los evaluadores persisten, la percepción de saturación del trabajo de la agencia también. Y esta permanencia no solo se evidencia en los testimonios sino en los documentos de evaluación interna y externa de la CONEAU, elaborados entre el 2000 y el 2012 (CONEAU, 2002; 201 1; 2012).

Existe asimismo un reconocimiento por parte de los evaluados del valor diferencial que otorga el hecho de poseer un saber específico, consistente en saber hacer buenas presentaciones, el "saber CONEAU", que hace posible que una buena carrera pueda ser evaluada negativamente o viceversa. El patrón común en este aspecto está en la actitud de los evaluados de buscar estrategias que permitan despejar las posibles arbitrariedades de sus colegas evaluadores, a través de la adquisición por distintos medios de ese saber específico.

Mi experiencia como par evaluador fue bastante 'shockeante' como te dije. Pensé que iba a ser otra cosa en el sentido de
un trabajo más estrecho con colegas de mi área. Lo que sí te puedo decir es que me sirvió un montón para saber qué es lo
que le interesa a la CONEAU evaluar. Cómo poner la información en los formularios, saber lo que les hacen ver a los pares
que luego dan un juicio. ... Me sirvió para saber cómo moverme cuando mi carrera sea evaluada. Y también saber que detrás
del dictamen apenas está el juicio de un evaluador, y que la suerte es un factor importantísimo. Si te tocó alguien con quien
no te llevás muy bien, hay probabilidades de que tu evaluación tenga problemas. Entonces la habilidad de hacer una buena
presentación en los papeles es fundamental. (Testimonio de un evaluador)

Entre esas estrategias se encuentra, por ejemplo, recurrir a personal externo especializado en cómo armar los informes, incluso a riesgo de sacrificar las bases conceptuales sobre las que se conciben las carreras.

Vino el famoso asesor que la universidad contrata y corrimos con los papeles para presentarla. Hicimos modificaciones a la carrera. Este asesor nos sugirió cosas que no estuve de acuerdo. Quiso hacer un FODA, y una carrera de posgrado. Para mí, no tiene amenazas. ... En el plan de mejoras tuve mucha discusión con este asesor. ... El se ponía como abogado del diablo como si fuera la CONEAU. Pretendía que la carrera fuera muy instrumental. El, yo creo, es un tipo de CONEAU. Te bate la justa de cómo es la cosa. Participa en cosas de CONEAU y viene a asesorar. A mí hay cosas que no me convencen de ese rol. Pero es valorado porque conoce el "metier" de cómo hay que hacer los papeles. Él me dijo qué era lo que tenía que prometer para mejorar la carrera. Yo trate de hacerlo realista y no poner cualquier cosa. Yo tengo una estructura cognitiva de armado de la carrera. Y él eso me lo objetaba, Quería cosas más estructuradas. Yo me planté y él termino aceptándolo. Y eso después fue valorado en la evaluación. (Testimonio de un evaluador)

Estas estrategias adaptativas no son casos aislados. Díaz-Barriga (2005), para el contexto mexicano, reconoce el surgimiento de un mercado de expertos en evaluación de los cuales lo máximo que se puede esperar es la aplicación de un saber específico. También distingue las estrategias adaptativas y simuladas, al formalizarse respuestas basadas en lo que se supone que el evaluador espera o quiere ver. Esto comentaba un director de carrera de grado: 
Nosotros pensábamos: vos sos CONEAU, OK, ¿qué querés que te ponga? ¿que haga tal cosa?... bueno, y después sería el problema del próximo Decano; y pusimos lo que CONEAU quería escuchar... no había matices. (Testimonio de un evaluado)

En ninguno de estos casos se han observado instancias de procesamiento o transformación de esas estrategias para mejorar el funcionamiento interno, es decir, una retroalimentación institucional más que procesos con finalidad propia. No obstante, es evidente que en los casos que se observan esas conductas adaptativas hubo un cambio, originado por la reacción a factores externos.

La adquisición de ese saber por parte de los evaluados asegura una buena apropiación de la racionalidad instrumental de la agencia y a la vez funciona como medio para neutralizar los posibles sesgos de los evaluadores, producto de la pertenencia a una comunidad académica. En este caso, la tensión del evaluado con sus colegas evaluadores está entre la valoración de los aportes recibidos por parte de una autoridad reconocida, o el temor que los juicios de sus pares estén imbuidos de visiones y modelos únicos, provenientes de sus instituciones, escuelas de pensamiento, o modos de concebir determinado funcionamiento de una carrera.

Los miembros y técnicos también han reconocido en los evaluados una actitud de obediencia formal, que se refleja, por ejemplo, en la elaboración de planes de mejora complacientes, o en la no defensa de las propuestas y aceptación sin mayores objeciones de las recomendaciones de los pares evaluadores. La tensión en el caso de los evaluados, está entre la simulación o la conducta adaptativa, es decir asumir a la acreditación como un requisito de control burocrático, necesario para sobrevivir y seguir compitiendo en el mercado, o aprovechar el proceso como mecanismo de mejora, en el mejor de los casos, haciendo confluir los objetivos e instrumentos externos con los de la gestión cotidiana de cara al cambio institucional genuino.

No se ha observado en ninguno de los testimonios de los evaluados que éste sea un propósito de la agencia. Pese a los esfuerzos manifestados por miembros y técnicos de dotar a los procesos de acreditación de un componente para el mejoramiento, que ha sido producto de un trabajo intenso al momento de diseño y puesta en marcha de las acreditaciones de grado, y más recientemente en posgrado, así como la oferta de cursos en los que se capacita a los responsables de carrera sobre cómo preparar las acreditaciones, la CONEAU es concebida como un organismo de control y regulación, para la mayoría, necesario, para otros, inevitable. Pero en términos generales, una agencia aceptada.

Esta situación permite interrogarnos sobre la idea de gradualidad hacia la consolidación del sistema de evaluación, así como en el significado del difuso concepto de “cultura de la evaluación”. La burocratización al interior de las instituciones y el consumo del tiempo en las nuevas tareas vinculadas a la evaluación pueden afectar el cumplimiento de las funciones sustantivas de la universidad (Díaz Barriga, 2005, 2008). Cuando se hace referencia a la aceptación e incorporación en las instituciones de la política de acreditación, es necesario incluir, en el análisis, las estrategias puestas en juego, junto con los valores, creencias y actitudes más o menos calculadas de los actores en cada contexto institucional.

El gran interrogante es si intentando ver el "trazo grueso" de la experiencia de acreditación acumulada hasta ahora, estos procesos constituyen en las instituciones lentos movimientos hacia el cambio (Clark, 1991) y, en ese caso, qué tipo de cambio. Las instituciones evaluadas pueden estar experimentando cambios provocados por procesos exógenos, por tanto reactivos y adaptativos. Estos podrían transformarse en cambios sustantivos en la medida en que se vayan complejizando al combinarse con las dinámicas internas. No se ha observado, de manera clara, esta tendencia en la situación actual de la acreditación de carreras por parte de la CONEAU. Aunque es innegable que, desde su existencia, las instituciones han cambiado como producto de su accionar.

\section{EQUILIBRIOS Y DESEQUILIBRIOS EN PERMANENTE TENSIÓN}

Cada uno de los actores identificados actuó en un ámbito en el que predominó un criterio de poder y autoridad. Los pares evaluadores, en el ámbito de las comunidades académicas, estuvieron guiados por una racionalidad vinculada a la distribución de prestigio dentro de sus respectivos campos. La autoridad 
reconocida a partir de su saber en un campo disciplinar los coloca en el rol indiscutible de evaluador o evaluadora de sus colegas. Sus intereses en hacer prevalecer sus cosmovisiones acerca de lo que "está bien" en la formación en su campo, resultan en juicios que pueden estar sesgados por esos intereses. Considerando la indagación realizada a partir de las entrevistas, podría decirse que el accionar de los pares académicos en los procesos de acreditación analizados es el resultado de dos factores: a) lo que se espera de ellos de acuerdo con un rol preestablecido en instancias como las normas o la capacitación, b) su pertenencia a un campo disciplinar en el que se suscita, en términos de Bourdieu $(1983,1988)$ una "pugna para determinar las condiciones y criterios de pertenencia y la jerarquía legítimas para decir la verdad” (Marquina, Ramírez y Rebello, 2009, p. 76), en este caso, respecto del buen funcionamiento de carreras de grado y posgrado en un área disciplinar. El accionar de los pares evaluadores, de esta forma, enfrenta la tensión entre su autoridad legítima producto de su conocimiento experto y sus intereses en el campo académico (ver Figura 2). El equilibrio deseado deberá inclinarse hacia el mayor peso del saber experto más que al poder en el campo académico.
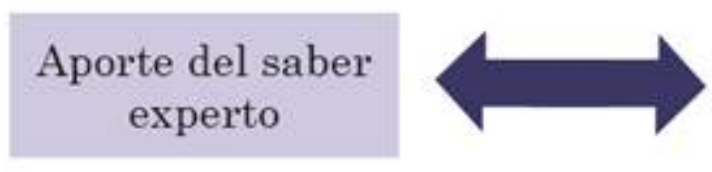

\section{Poder y autoridad en su campo}

FIGURA 2

La tensión en el ámbito de la oligarquía académica

La CONEAU ha sido la agencia que en el ámbito del Estado tuvo la función de implementar un nuevo instrumento de política pública, como es la evaluación. En su interior, técnicos y miembros han dado vida al organismo, transformando los marcos dados por la ley en pautas, criterios y valores que fueron dando un sentido a la evaluación. Esta construcción también estuvo en permanente tensión desde sus comienzos, reflejada en el tipo de perfil que a lo largo de su historia se le ha querido dar a la agencia. Hemos visto en los testimonios analizados que la inicial impronta gerencial chocó inmediatamente con la necesidad de abrir el espacio a un modelo más flexible de negociación, para hacer frente a la resistencia ejercida por la comunidad universitaria. Este perfil permitió desarrollar una actitud reflexiva de los procesos al ritmo en que se iban implementando. Y a la vez que generaba apertura y cierta recepción por parte del sistema, también dio cuenta de inconsistencias propias del carácter político y no gerencial del organismo. Con la creciente carga de trabajo, y la exigencia externa de actuar como organismo fiscalizador, las contradicciones comenzaron a profundizarse. Acreditar cada vez más carreras implicó un aumento exponencial de la carga de trabajo del organismo, que ya tenía diseñados sus procesos y sus instrumentos. La urgencia por hacer frente al crecimiento fue dando cada vez menos espacio a la reflexión y más lugar al poder de la racionalidad instrumental. La tensión en el ámbito del Estado (ver Figura 3) se expresa entre la lógica política y la burocrática. El equilibrio deseado debiera expresarse en una suerte de paridad, de manera que se pueda lograr lo que Weber (1998) ha denominado como una racionalidad instrumental "maduramente reflexionada".
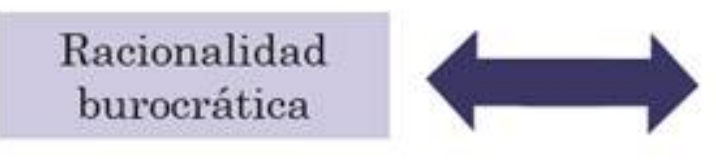

FIGURA 3

La tensión en el ámbito del Estado

\section{Racionalidad política}


Hemos identificado a "los evaluados" como actores comprometidos con las carreras que dirigen. En el ámbito de un mercado caracterizado ya sea por la competencia por estudiantes, o bien por prestigio de los programas, o bien por recursos disponibles, los “evaluados” tienen intereses específicos en la acreditación, ya sea de carreras de grado como de posgrado. Reconocen a la CONEAU como un ámbito que puede ser determinante en esa distribución de bienes materiales y simbólicos. Y en ese marco aceptaron la política de la acreditación por variadas razones. Los más reactivos la asumieron como un requisito inevitable de control externo, que a la vez fue necesario para no quedarse atrás en una competencia que asumen como ilegítima. Los más activos, entienden que la acreditación es la llave para mostrar calidad en el mercado de estudiantes. Entre ellos, están los interesados en insertarse al sistema y buscan abrir espacios de interlocución con el Estado. También están quienes necesitan de pautas e instrumentos para perfeccionar sus más o menos maduros sistemas de gestión institucionales o de las carreras. En términos generales, han tomado las nuevas reglas de juego como condicionantes externos. Cómo incorporarlas al funcionamiento cotidiano de sus carreras ha sido una cuestión solo para algunos.

Un bien preciado, en este marco, es adquirir un saber específico de la acreditación, que hemos denominado el "saber CONEAU". Este saber consiste en demostrar, a través de los procedimientos, que cumplen con lo que se espera de ellos, y de esto puede depender la acreditación de una carrera. Que efectivamente esos requerimientos mínimos, dados por los estándares, se cumplan o no, no parece ser la principal preocupación. Por ello, han desarrollado estrategias adaptativas, ya sea complacientes con las recomendaciones, ya sea replicando fórmulas que se saben exitosas a la vista de los evaluadores, ya sea contratando expertos en ese "saber CONEAU" que le puede dar pistas claves para una buena presentación. Hay una realidad, y es que la CONEAU es una entidad reconocida. De lo contrario, no generaría ningún tipo de respuesta en las instituciones. El reconocimiento de la CONEAU como control externo activa una actitud reactiva y adaptativa al cambio. Y cuanto más adaptativas son las conductas de los evaluados menores son las posibilidades de recibir a la evaluación como opción para mejorar las carreras. En este sentido, la principal tensión subyacente en este ámbito está entre simular o cambiar, y en donde, al igual que en primer ámbito, la situación deseable es que predomine el peso de la tensión en el cambio (ver Figura 4).
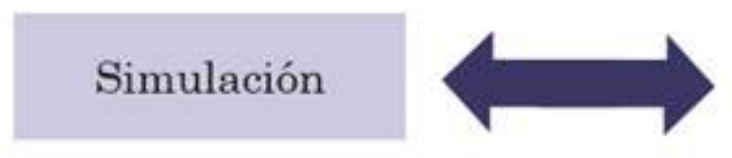

\section{Cambio}

\section{FIGURA 4}

La tensión en el ámbito del mercado

En principio, para atender la complejidad de lo que denominamos "la arena evaluativa", se hace necesario reconocer que las tensiones mencionadas son constitutivas de dicha arena. Estas mismas no se resuelven ni disuelven en síntesis superadoras. Sobreviven en una suerte de equilibrios o desequilibrios que hemos intentado caracterizar.

Partiendo de esta premisa, fue necesario ir más allá de las tensiones internas de cada ámbito, y ver cómo influyen en dichas tensiones internas las acciones y los actores pertenecientes a otros ámbitos. Hemos observado cierto consenso en que los problemas inevitables en la tarea de evaluar de los pares, expresados en la existencia de sesgos producto de la pertenencia a campos disciplinares, se neutralizan perfeccionando los instrumentos en el marco de los cuales los evaluadores realizan sus juicios. Así, el equilibrio necesario en el ámbito académico entre el saber experto y la búsqueda de poder y autoridad se logra con el aporte de un elemento proveniente de la agencia estatal: los instrumentos. Esta incursión puede asegurar, en principio, el equilibrio necesario en el ámbito de los evaluadores para lograr el objetivo de que formulen juicios fundados a partir de un saber reconocido. Pero también la tensión interna de los evaluadores se regula a partir de la 
legitimidad de su tarea otorgada por los evaluados. Una actuación manifiestamente sesgada del evaluador pondría en riesgo el reconocimiento que necesita para mantener su prestigio. Por lo que, si existe un interés desmedido en actuar como "guardián" de visiones establecidas respecto de cómo debe ser una carrera, con base en modelos concebidos como únicos, la reacción proveniente del ámbito de los evaluadores puede afectar su credibilidad. En este sentido, la mirada del evaluado respecto del reconocimiento en el evaluador de un saber o autorizado, o impuesto, también opera como equilibrador de la tensión interna del evaluador.

En el ámbito del Estado, la principal tensión entre la racionalidad burocrática y la política que atraviesa la agencia a lo largo de su existencia es regulada por elementos provenientes de los otros ámbitos. Una extremada aplicación de los instrumentos puede operar, a los ojos del evaluador, como un factor que transforma al trabajo del par en un aplicador de normas o, incluso, en legitimador de resultados que a priori ya están dados por el saber instrumental. La tarea del par evaluador se reduciría a un "checklist" de condiciones a cumplir que ya están previstas de antemano. Por lo que a la agencia le va a interesar obtener del evaluador su saber disciplinar, y traducir ese interés en los instrumentos, poniéndolos en discusión si fuera necesario, y ajustándolos en función de la realidad que veces dista mucho de lo establecido en las normas. El saber disciplinar del evaluador puede, en este sentido, colaborar con el equilibrio interno de la agencia entre la aplicación de la cruda racionalidad instrumental y su combinación con la racionalidad política. Por su parte, el equilibrio de tensiones internas de la agencia también puede recibir el aporte del ámbito del mercado. Desde allí la CONEAU recibe una respuesta que colabora con su propia existencia. La CONEAU por parte de los evaluados puede ser reconocida como fuente de fiscalización estatal que reforzaría su faz burocrática. $\mathrm{Su}$ reconocimiento, por el contrario, puede estar basado en una legitimidad reconocida por el aporte al mejoramiento de las carreras, lo que reforzaría aún más la faz reflexiva de la agencia.

Finalmente, el equilibrio deseado en el ámbito de los evaluados, entre una aceptación formal de la evaluación como requerimiento externo y la apropiación de estos procesos para el logro de la mejora, o sea en la tensión entre la simulación y el cambio, se asegura con elementos provenientes de los otros ámbitos. La incorporación de aspectos tendientes a la mejora en la metodología desarrollada por la agencia para llevar adelante la acreditación, que como vimos tiene rasgos de control per se, colabora con el cambio sustantivo en las carreras. Por el contrario, procesos e instrumentos imbuidos de una mirada de la evaluación como control desde la agencia activará la reacción y la adaptación, es decir, el cambio exógeno, o la mera simulación. Por su parte, el ámbito de los evaluadores colabora en el equilibrio de la tensión subyacente en los evaluados. El predominio de los intereses particulares de la comunidad disciplinar o de la imposición de modelos únicos refuerza el extremo de la simulación en el accionar de los evaluados. El aporte del juicio del evaluador basado en su saber disciplinar autorizado colabora con el cambio sustantivo en la carrera.

\section{Conclusiones: Hacia un MODELO CONCEPTUAL}

Las tensiones internas y externas hasta aquí explicadas pueden graficarse en la Figura 5: 

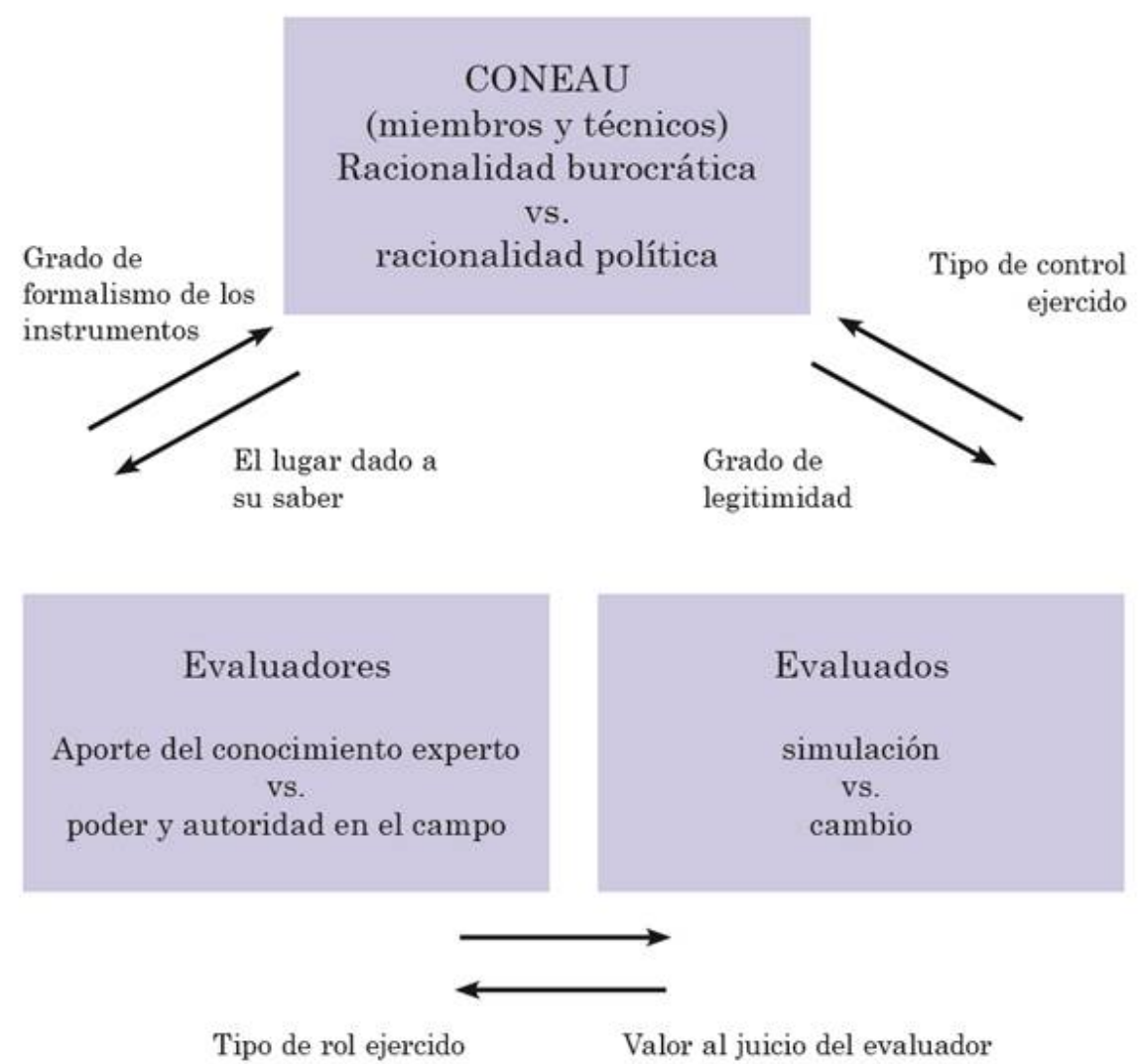

FIGURA 5

La arena evaluativa. Modelo de equilibrios y tensiones

Puesto en funcionamiento, el modelo permite reconocer distintos circuitos, según se alcance el equilibrio deseado en la tensión interna en cada ámbito. Podemos pensar en dos casos extremos, uno que podemos calificar como el más virtuoso y otro como el más vicioso.

El circuito más virtuoso estaría dado cuando las tensiones al interior de cada ámbito están controladas, no solo por las acciones de sus actores sino porque el elemento externo que ejerce influencia sobre el ámbito colabora con el equilibrio interno. En este sentido, podemos pensar en una situación virtuosa en la que en el ámbito de los evaluadores predomina el aporte del conocimiento experto por sobre los intereses vinculados a las pugnas en las comunidades académicas. Este equilibrio se ha logrado porque los instrumentos provenientes de la agencia ayudan a neutralizar los sesgos, y porque hay un interés por parte de los evaluadores de que su aporte sea altamente valorado por quien es evaluado. En este circuito virtuoso la agencia también ha encontrado una armonía en su accionar entre la racionalidad instrumental dada por el desarrollo de metodologías e instrumentos que son fundamentales para el funcionamiento del sistema y una permanente mirada reflexiva sobre el desarrollo de los procesos, que dé lugar a cambios, ajustes y perfeccionamientos surgidos como productos de la propia práctica. En esta situación reflexiva también hay especial cuidado porque estos ajustes no sean arbitrarios sino que se realicen con arreglo a un interés permanente por el cumplimiento de los objetivos de control y a la vez de mejora de las carreras. El circuito virtuoso se cierra en el ámbito de los evaluados -aunque demás está decir que podríamos haber comenzado y culminado en cualquiera de los tres ámbitos. En este ámbito del mercado la acreditación es recibida como un bien necesario para competir pero a la vez como elemento constitutivo de procesos internos de gestión y mejora permanente. Hay un reconocimiento de la agencia evaluadora dado tanto por su función fiscalizadora como por su aporte a la mejora. Y el juicio del evaluador es valorado en el mismo sentido. 
En este circuito virtuoso las tensiones se autorregulan según se logre el contrapeso deseado en cada una las tensiones. Predomina el rol del evaluador como conocedor, experto, y colaborador a partir de su conocimiento, el rol del evaluado como receptor del aporte recibido desde la evaluación para incorporarlo a sus procesos de mejora continua; y una agencia que en permanente revisión de sus procesos e instrumentos aporta racionalidad a las posibles tensiones dadas entre evaluadores y evaluados, manteniendo internamente un equilibrio entre el criterio político y el funcionamiento autónomo de los procedimientos. En este circuito es posible concebir a la evaluación como facilitadora de la mejora y el cambio, y hay espacio para la reflexión, la participación y la construcción colectiva de sentidos de todos los actores involucrados.

En el otro extremo encontramos un circuito vicioso, en el que se exacerban los aspectos no deseados en cada uno de los ámbitos, no pudiéndose lograr el propósito de la evaluación como mecanismo de mejora de la calidad. En este escenario, predominan los intereses de los evaluadores por mayor poder o autoridad en sus campos, plasmado en juicios sesgados por estos intereses y por la imposición de visiones únicas y hegemónicas acerca de cómo debe ser una carrera y una institución. Los evaluados son conscientes de ello, por lo que desvalorizan la posibilidad de recibir recomendaciones útiles para el funcionamiento de sus carreras por parte de los pares evaluadores. En su actitud ante la acreditación predomina el formalismo, las estrategias adaptativas, la simulación. Es importante responder al control ejercido por la agencia de la mejor manera posible. Para ello es clave saber hacer buenas presentaciones, recurriendo a expertos externos si fuera necesario. Acreditar es un consumo de tiempo, adicional a la gestión cotidiana de la carrera. Pero es necesaria para existir, para competir por más estudiantes, recursos o prestigio. Y para cumplir con una exigencia externa, con la ley.

En este circuito vicioso la agencia funciona como una máquina. Apenas puede con su creciente carga de actividad. O bien ha convertido en rutina sus procesos, los cuales ya están establecidos, por lo que solo se requiere personal que los aplique, sin una necesaria revisión de estos; o bien hay espacio para la intromisión de criterios políticos arbitrarios ante problemas no resueltos producto de la no revisión de los procedimientos. Esta imagen de la agencia es recibida por los evaluados y los evaluadores. Los primeros se quejan de las exigencias formales resultantes del tipo de control fiscalizador ejercido por la agencia evaluadora. Los segundos cada vez tienen menos interés en formar parte de esos procesos, ya que el lugar del saber disciplinar que ellos pueden aportar es muy acotado y se desdibuja en los instrumentos diseñados. Se incomodan al observar que su rol está limitado al llenado de formularios. Además, la función no retroalimenta significativamente su poder dentro del campo disciplinar.

De más está decir que estos dos circuitos son tipos ideales. No existen como tales en la realidad. Pero sirven como marcos para pensar los muchos otros circuitos que se generan en la arena evaluativa, según predominen en más o en menos los elementos en tensión analizados. Si el modelo fuera efectivo, sería posible ubicar en él las diferentes situaciones que hoy se presentan cuando se llevan adelante las acreditaciones. Y podría servir para evaluar modos de neutralización de los vicios o fortalecimiento de las virtudes. O simplemente habrá cumplido con el fin de mostrar que el complejo proceso de desarrollo de la acreditación no es lineal ni es gradual.

Salir de la mirada lineal y gradual ha permitido entender la acreditación como instrumento de política pública, en su complejidad. Sin embargo, queda pendiente preguntarnos, si estamos en presencia de un juego de equilibrios estáticos. ¿Hacia dónde va el sistema de evaluación argentino? ¿Tiene un sentido? Hay una realidad innegable, y es que la evaluación como política se ha introducido en las instituciones y provocó cambios. Se podrá hablar de una consolidación de la política de evaluación, pero ello no debería significar necesariamente una consolidación virtuosa. Si hay un sentido, este deberá ser comprendido desde las instancias políticas en todas sus dimensiones. Dos décadas de experiencia son un buen lapso para hacer balances, aunque será preciso salir de las visiones lineales, si es que se sigue pensando en producir políticas para generar cambios orientados al logro de la calidad en las universidades. Sería un error seguir pensando que el éxito de la política de evaluación se produce cuando se logra la "cultura de la evaluación”. Lejos de 
esa idea, la cultura de la evaluación ya está presente y ha sido nuestro objeto de estudio. Es la que sostiene el entramado de relaciones, tensiones e intereses presentes en la arena evaluativa. Es la que subyace al accionar de actores situados en instituciones, que de manera permanente construyen creencias y valores que dan sentido a la evaluación.

\section{ReFERENCIAS}

Archenti, N. y Piovani, J. (2007). Los debates metodológicos contemporáneos. En A. Marradi, N. Archenti y J. Piovani, (Auts.). Metodología de las ciencias sociales (pp. 29-44). Buenos Aires: Emecé editores.

Becher, T. y Trowler, P. (2001). Academic tribes and territories. [Tribus académicas y territorios] (2a ed.). Buckingham: The Society for Research into Higher Education (SRHE) and The Open University Press.

Bourdieu, P. (1983). Campo de poder y campo intelectual. Buenos Aires: Folios Ediciones.

Bourdieu, P. (1988). Homo Academicus. California: Standford University Press.

Buendía, M. A. (2011a). Análisis institucional y educación superior. Aportes teóricos y resultados empíricos. Perfiles Educativos, 33(134), 8-33. Recuperado de http://www.iisue.unam.mx/perfiles2/index.php/article/view/27938

Buendía, M. A. (2011b). Simulación, falta de credibilidad, burocratización El lado oscuro de la evaluación y acreditación. Recuperado de http://laisumedu.org/showNota.php? idNota $=211678 \&$ cates $=\&$ idSubCat $=\&$ subcates $=\& s s c=\& m=$ mail $1 \& p=$ mail 1

Camou, A. (2007). Los “juegos” de la evaluación universitaria en la Argentina. Notas sobre las interacciones conflictivas entre Estado y universidad. En P. Krotsch, A. Camou y M. Prati (Coords.), Evaluando la evaluación: Políticas universitarias, instituciones y actores en Argentina y América. Buenos Aires: Prometeo Libros.

Clark, B. (1991). El sistema de educación superior. Una visión comparativa de la organización académica. México DC: Nueva imagen.

Comisión Nacional de Evaluación y Acreditación Universitaria (CONEAU). (2002). Contribuciones para un análisis del impacto del sistema de evaluación y acreditación. Recuperado de http://www.coneau.edu.ar/archivos/ Impacto.pdf

CONEAU. (2011). Avances de gestión desde la evaluación institucional. Recuperado de http://www.coneau.edu.ar/ archivos/publicaciones/documentos/AvancesdeGestion.pdf

CONEAU. (2012). La CONEAU y el sistema universitario argentino. Recuperado de http://www.coneau.edu.ar/ archivos/publicaciones/documentos/La_CONEAU_y_el_sistema_universitario_argentino.pdf

Corengia, Á. (2015). El impacto de la CONEAU en las universidades argentinas. Estudio de casos. Buenos Aires: Teseo y Universidad Austral.

Diaz-Barriga, Á. (2000). Evaluar lo académico. Organismos internacionales, nuevas reglas y desafíos. En T. Pacheco Méndez y A. Díaz Barriga (Aut), La evaluación académica. (Pp. 11-31) México D.F.: UNAM, CESU: CFE.

Diaz-Barriga, A. (junio, 2005). Riesgos de la evaluación y acreditación de la educación superior. Trabajo presentado en el Seminario regional: Las nuevas tendencias de la evaluación y la acreditación en América Latina y el Caribe, Buenos Aires. Recuperado de http://www.angeldiazbarriga.com/ponencias/riesgos_sistemas_acreditacion.pdf

Díaz-Barriga, Á. (2008). Impacto de la evaluación en la educación superior mexicana. México D.F.: Universidad Nacional Autónoma de México, Instituto de Investigaciones sobre la Universidad y la Educación.

Dias-Sobrinho, J. (2003). Avaliaçao da educaçao superior regulaçao e emancipaçao. Avaliaçao, 8(2), 31-47.

Dias-Sobrinho, J. (junio, 2005). Impactos de la evaluación y la acreditación en América Latina y el Caribe. Trabajo presentado en el Seminario regional: Las nuevas tendencias de la evaluación y la acreditación en América Latina y el Caribe. Buenos Aires. ISALC - CONEAU.

Dias-Sobrinho, J. (2006). Paradigmas e políticas de avaliação da educação superior. Autonomia y heterônomia. En H. Vessuri (Comp.) Universidad e investigación científica: Convergencias y tensiones. (pp.169-191) Buenos Aires: CLACSO - UNESCO. 
Dias-Sobrinho, J. (2008). Avaliacao Educativa: produção de sentidos com valor de formação. Avaliacao, 13(1), 193-207.

Fortes, M. y Malo, S. (2002). Una revisión de las evaluaciones por comités de pares. Trabajo presentado en el V Foro de Evaluación Educativa. Ensenada. CENEVAL.

Harvey, L. (1999). Evaluating the evaluators. [Evaluando a los evaluadores]. Trabajo presentado en la conferencia inaugural de la Quinta Conferencia Bienal de la International Network of Quality Assurance Agencies in Higher Education (INQAAHE). Birmingham: Centre for Research into Quality, University of Central England in Birmingham.

Instituto Internacional para la Educación Superior en América Latina y el Caribe (IESALC). (2007). Informe de evaluación externa de la Comisión Nacional de Evaluación y Acreditación Universitaria (CONEAU). Recuperado de www.coneau.edu.ar/archivos/InformeEvExCONEAU.pdf

Isuani, E. (2003). Estudio sobre algunos resultados de la labor de la CONEAU. Recuperado de http:// www.coneau.gov.ar/archivos/1337.pdf

López, A. (2005). Los fundamentos de la nueva gestión pública: Lógica privada y poder tecnocrático en el Estado mínimo. En M. Thwaites y A. López (Eds.), Entre tecnócratas globalizados y políticos clientelistas. Derrotero del ajuste neoliberal en el Estado argentino. (pp.69-88). Buenos Aires: Prometeo.

Marquina, M., Ramírez, B. y Rebello, G. (2009). La actuación de pares evaluadores de carreras de posgrado: Percepciones desde el propio campo académico. Revista Argentina de Educación Superior (RAES), 1(1), 57-77. Recuperado de http://www.revistaraes.net/revistas/raes1_art3.pdf

Neave, G. (2001). Educación superior: Historia y política. Estudios comparativos sobre la universidad contemporánea. Barcelona: Gedisa.

Oszlak, O. y O'Donell. G. (1981). Estado y políticas estatales en América Latina: Hacia una estrategia de investigación. Buenos Aires: Centro de Estudios de Estado y Sociedad (CEDES). Recuperado de http://www.oscaroszlak.org.ar/images/articulos-espanol/Oszlak\%20y\%20O\%20Donnell\%20\%20Estado \%20y\%20Politicas\%20Estatales.pdf

Pilot, A. (abril, 2001). Quality assurance and accreditation in higher education in the Netherlands: internal quality care and external quality assessment. [Aseguramiento de la calidad y acreditación en educación superior en Holanda: Cuidado interno de la calidad y medición externa de la calidad]. Trabajo presentado en la Conferencia sobre garantía de calidad y acreditación en la educación universitaria rumana, Bucarest.

Porter, L. (2003). La universidad de papel: Ensayos sobre la educación superior en México. México D.F.: Editorial Universidad Nacional Autónoma de México.

Powell, W.y Dimaggio, P. (1991). Introducción. En W. Powell y P. Dimaggio, El nuevo institucionalismo en el análisis organizacional. (pp. 33-34). Mexico: Fondo de Cultura Económica.

Presidencia de la Nación. (1995). Ley de Educación Superior N.o 24.521. Recuperado de http://www.me.gov.ar/ consejo/cf_leysuperior.html\#titulo

Roy, R. (1984). Alternatives to review by peers: a contribution to the theory of scientific choice [Alternativas a la revisión por pares: Una contribución a la teoría de la elección científica]. Minerva, 22(3-4),316-328. doi: https:// doi.org/10.1007/bf02207367

Travis, G. y Collins, H. (1991). New light on old boys: Cognitive and institutional particularism in the peer review system. [Nueva luz sobre los viejos muchachos: El particularismo cognitivo e institucional en el sistema de revisión por pares]. Science, Technology, and Human Values, 16(3), 322-341.

Weber, M. (1998). El Político y el científico. Madrid: Alianza Editorial.

\section{Notas}

[2] Se trata de títulos correspondientes a profesiones reguladas por el Estado, cuyo ejercicio pudiera comprometer el interés público poniendo en riesgo de modo directo la salud, la seguridad, los derechos, los bienes o la formación de los habitantes.

(Presidencia de la Nación, 1995, art. 43). 
Mónica Marquina. Equilibrios y tensiones en dos décadas de aCreditación universitaria en Argentina...

[3] El cuestionario se organizó en cuatro partes: 1) datos personales y laborales; 2) capacitación; 3) trabajo efectivamente realizado en el rol de evaluador; 4) opinión del encuestado acerca del sistema de evaluación y su evaluación de la experiencia como evaluador. Se realizó el procesamiento a través de una base estadística SPSS que permitió encontrar regularidades y diferencias en las respuestas, que luego fueron complementadas con las entrevistas en profundidad que permitieron indagar en loss fundamentos. Los resultados de la encuesta fueron analizados preliminarmente en Marquina, Ramírez y Rebello (2009).

[4] El procesamiento y análisis se realizó con apoyo de Atlas T, a través del cual se identificaron consensos y disensos según el objetivo de indagación en cada grupo entrevistado.

[5] Ordenanza CONEAU 13/97 vs. Ordenanza CONEAU No 42/2005.

[6] Ordenanza CONEAU Nro. 46/2005.

[7] Decreto $173 / 96$.

[8] En el año 2009, el área de Desarrollo y Relaciones Internacionales se convierte en Dirección, lo que fue percibido por varios técnicos como una disociación entre la innovación y el trabajo cotidiano. Testimonio de un técnico: "El área de desarrollo es la más bastardeada por las otras áreas porque les vienen a romper la rutina... 'Vamos todos a escuchar la charla de..." y no va nadie... Sin embargo, ese es el único dispositivo que hoy tiene la CONEAU para no morir. Cuando hicieron la autoevaluación de la CONEAU equivocadamente se la dieron al área de evaluación institucional, y no a esta área. Y fue una pena. Y pusieron a dos consultores externos a hacer la autoevaluación, y fue un desastre. Sin participación del área de desarrollo. Fue un error”.

\section{BY-NC-ND}

